\title{
Cybersecurity, intelligent multimedia systems for threat detection and data protection
}

Published online: 5 March 2022

(C) Springer Science+Business Media, LLC, part of Springer Nature 2022

Multimedia Tools and Applications gratefully acknowledges the editorial work of the scholars listed below on the special issue entitled "Cybersecurity, Intelligent Multimedia Systems for Threat Detection and Data Protection” (SI 1180).

Of 60 papers submitted, 5 were accepted for this issue after a stringent peer review process.

\section{Corresponding Guest Editor}

Andrzej Dziech

AGH University of Science and Technology, Krakow, Poland

Email: dziech@kt.agh.edu.pl

\section{Guest Editors}

Wim Mees

Royal Military Academy, Brussels, Belgium

Email: wim.mees@rma.ac.be

Publisher's note Springer Nature remains neutral with regard to jurisdictional claims in published maps and institutional affiliations. 